\title{
A MEDIAÇÃO EM SALA DE AULA COMO CONSTRUÇÃO PARTILHADA DE SENTIDOS
}

\author{
MARIA JUDITH ISMAEL RIGHI-GOMES ${ }^{1}$ \\ SECRETARIA DE EDUCAÇÃO DO ESTADO DE SÃO PAULO
}

\begin{abstract}
RESUMO: Este texto sobre mediação em sala de aula é dedicado à $\operatorname{Prof}^{\mathrm{a}} \operatorname{Dr}^{\mathrm{a}}$ Maria Irma Coudry que, desde a criação da área da Neurolinguística Discursiva, muito tem contribuído para refletir sobre patologização, medicalização e mediação, temas que permeiam as discussões sobre a prática pedagógica em nossos dias. O texto se fundamenta em um dos conceitos presentes em sua obra, Diário de Narciso: discurso e afasia, o de "construção partilhada de sentidos", introduzido para questionar a padronização das avaliações e práticas terapêuticas com sujeitos afásicos. As reflexões realizadas por Coudry (1986) sobre construir sentidos através da linguagem, para que as interlocuções se tornem significativas e permitindo que os sujeitos assumam seus posicionamentos históricos, abrem um campo muito fértil para a compreensão do que significa "mediar" no contexto escolar. Ao reconhecer no aluno um sujeito de linguagem e, por isso, dependente das relações que se estabelecem em seu meio, o referido conceito atua como um contradispositivo às metodologias padronizantes, implantadas por políticas públicas e vigentes na escola atual. A reflexão aqui realizada se fundamenta em diversos autores da Neurolinguística Discursiva, em especial Coudry (1986; 1996; 2010), Freud (1891;1895), Vygotsky $(1926 ; 1934)$ e Luria $(1977 ; 1979)$, relacionando o funcionamento cerebral ao simbólico e ao histórico.
\end{abstract}

Palavras-chave: Neurolinguística Discursiva; Linguagem; Sala de aula; Mediação; Aprendizagem.

ABSTRACT: This essay on classroom mediation is dedicated to Professor Maria Irma Coudry who, since the foundation of the area of Discursive Neurolinguistics, has greatly contributed to reflect on pathologization, medicalization and mediation, themes that permeate the discussions about pedagogical practice in our days. The text is based on one of the concepts present in her work, Diário de Narciso: discurso e afasia - the "shared construction of meanings", introduced to question the standardized assesssement and therapeutic practices with aphasic subjects. Coudry's (1986) reflections about building up sense through language aiming to turn interlocutions meaningful and to allow subjects to assume their historical positions open a very fertile field for understanding what "mediation" means in the school context. By recognizing the student as a subject of language, and therefore dependent on the relationships established in his/her environment, this concept acts as a counter-apparatus to the standard methodologies, implemented by public policies and current in the school. The reflection presented are based on several authors of the Discursive Neurolinguistics, especially Coudry (1986, 1996, 2010), Freud (1891, 1895), Vygotsky $(1926,1934)$ and Luria $(1977,1979)$, relating cerebral functioning to symbolic and historical shared sense construction.

Keywords: Discoursive Neurolinguistics; language; learning

${ }^{1}$ PEB II - Professora Ensino Básico Ciclo II 


\section{INTRODUÇ̃̃O}

Com base em uma reflexão sobre a importância do conceito de "construção partilhada de sentidos" para a reconstrução da linguagem em sujeitos afásicos, Coudry (1986) discute, em sua obra Diário de Narciso: Discurso e Afasia, questões sobre o apagamento do sujeito e sua história quando submetidos a testes e práticas terapêuticas. Essa padronização leva a uma classificação tipológica dos distúrbios afásicos que desconsidera o fato de que essas práticas agravam as dificuldades do sujeito afásico no exercício da linguagem. Sem clareza sobre o que dele se espera nos testes e/ou atividades, o sujeito, constantemente avaliado, é excluído de seu papel na interlocução e fica relegado à posição de paciente (COUDRY, 1986).

Contrária a essa abordagem e mantendo como eixo de sua prática o discurso, que valoriza as possibilidades interativas dos sujeitos, a autora funda o campo da Neurolinguística Discursiva (ND), entendendo que o trabalho com a linguagem, em contextos sócio-históricos significativos, cria vias de conexões cerebrais (vias alternativas em casos de lesões) que se tornam funcionais. Coudry (1986) enfatiza a relação entre cérebro e linguagem como constitutiva do ser humano, entendendo que tal relação - própria do ser humano - só se estabelece nas interações sociais, via linguagem.

Comprometida com uma visão sócio-histórica de sujeito desde o início dos trabalhos - na década de 80 no Centro de Convivência de Afásicos (CCA) - e atenta ao crescente número de crianças que recebem diagnósticos de alguma patologia por não terem aprendido a ler e a escrever, Coudry institui, em 2004, o CCazinho (Centro de Convivência em Linguagens), para realizar o acompanhamento dessas crianças. Sua percepção é a de que, tal como os afásicos, na entrada das crianças no processo de ler com compreensão e escrever com sentido é necessário, na prática, de interlocutores que impulsionem novas possibilidades de fala, leitura e escrita.

Desde o início, o CCazinho assume uma posição contra a patologização de crianças que não adquiriram a leitura e a escrita durante o processo de escolarização. Atribui esse fracasso escolar, dentre outras causas, às atividades padronizadas e pouco contextualizadas que são realizadas na escola (COUDRY e FREIRE, 2005; COUDRY, 2010). A ND abre, assim, um importante espaço para discussões sobre as práticas de ensino-aprendizagem, agregando importantes autores que realizaram análises essenciais para a compreensão dos processos que se relacionam ao Sistema Nervoso e às funções cognitivas. Dentre esses autores, citamos Freud (1891;1895), Luria $(1977 ; 1979)$ e Vygotsky $(1926 ; 1934)$, que contribuem para o movimento teórico da ND, apresentando o cérebro como um órgão dinâmico, desenvolvido nos contextos sócio-históricos, por meio da linguagem.

\section{AS PRÁticas PEDAGÓgICAS E A NEUROLINGUíSTICA DISCURSIVA}

Entender a prática pedagógica como uma construção partilhada de sentidos possibilita refletir sobre o processo de ensino-aprendizagem dentro do quadro 
teórico da ND, com vistas a entender e superar a padronização dessa prática. Tratase, portanto, de questões relativas à metodologia de ensino.

Com base na experiência como professora de Ciências Físicas e Biológicas do Ciclo II, em uma escola pública de uma região periférica de Campinas (SP), cotidianamente interpreto as dificuldades encontradas por meus alunos na formação de conceitos como decorrência da falta de familiaridade com determinadas práticas de linguagem. Essa inexperiência está relacionada à redução de vivências significativas com a fala, a leitura e a escrita, o que interfere com as possibilidades de interpretar o que a escola ensina, considerando que conceitos são representações mentais que se formam por meio da linguagem.

Vivências significativas com a linguagem pressupõem, de acordo com a ND, a valorização das possibilidades interativas dos sujeitos. Coudry (1986) ressalta que o trabalho deve sempre ser interacional e histórico e descreve o contexto como um espaço relacional estabelecido pelos interlocutores naquela situação particular. A escola, social e historicamente definida como o lugar de ensinar e de aprender, deveria ser o espaço relacional da mediação, sendo esta vista como o processo que integra tanto o professor - como ator ou interlocutor -, quanto o aluno e ainda o objeto de conhecimento. Isso só faz sentido quando se considera que o acesso do homem ao mundo não se dá de modo direto, mas por meio de símbolos semióticos, em especial, a linguagem (OLIVEIRA, 2007).

O conceito de "atividade mediada" (VYGOTSKY 1926; 1934) representa um grande avanço na compreensão dos processos cognitivos, já que é sempre na relação com o outro que o homem se torna um aprendiz. Mas, na escola pública não tem sido assim. A atividade mediada se encontra profundamente marcada por incompreensões que afetam a metodologia de ensino - geradas tanto pela implantação de políticas públicas, como pela falta de orientações significativas aos professores.

\section{METODOLOGIA DE ENSINO E POLÍTICAS PÚBLICAS}

Na década de 80, o Brasil apresentava altos índices de analfabetismo, bem como de repetência e evasão na, então, $1^{\mathrm{a}}$ série do Ensino Fundamental, fazendo com que políticas públicas de educação se voltassem à implantação de um ensino diferenciado para conter o fracasso escolar. É nesse contexto histórico que chega ao Brasil a concepção construtivista de alfabetização de Emília Ferreiro, com base na teoria epistemológica de Jean Piaget. Ferreiro (1996) afirma que, na medida em que as estruturas mentais inatas do sujeito vão amadurecendo, ao longo da vida, a criança se torna apta a assumir um papel ativo na construção de seu conhecimento, pois se torna motivada a buscar respostas para suas dúvidas e se auto-organiza para avançar nas etapas de aprendizagem, superando seus erros. Ferreiro (1996) afirma, inclusive, que a criança em seu papel ativo na aprendizagem não é um sujeito que espera que alguém que possua um conhecimento o transmita a ela, por um ato de benevolência (FERREIRO, op. cit., p. 26). 
Em 1983, o construtivismo como fundamentação teórica da metodologia de ensino é oficialmente assumido no Estado de São Paulo. A Secretaria de Educação do Estado de São Paulo (SEE) e a Coordenadoria de Estudos e Normas Pedagógicas (CENP) ofereciam, através do chamado Projeto Ipê, capacitações que chegavam à escola na forma de fascículos, programas de TV e, mais tarde, por meio de seminários. Essas atividades de capacitação, entretanto, não foram suficientes para esclarecer aos professores sobre o seu novo papel: o de facilitadores da aprendizagem da criança que tem uma "hipótese" sobre a qual trabalha sozinha. Sem compreender o significado de sua prática e sem receber apoio e acompanhamento em nome da "autonomia" do método, para o professor o ato de ensinar ficou marcado como algo negativo no construtivismo (DUARTE, 2012), pois poderia prejudicar o desenvolvimento da aprendizagem. O lema construtivista aprender a aprender, que propagava a ideia de que o sujeito deve aprender por si mesmo, a partir de estruturas mentais previamente adquiridas e amadurecidas, foi interpretado como um processo que prescinde do outro.

$\mathrm{Na}$ prática, as incompreensões geradas pela nova proposta de ensino caracterizaram o processo pedagógico pela ausência do outro na relação entre a criança e o conhecimento disciplinar. Essa ausência é compensada por uma padronização das atividades pedagógicas que leva ao apagamento de professores e alunos. O apagamento do aluno provoca desinteresse e apatia, geralmente, interpretados como indisciplina ou como patologias. Em alguns casos, chega a provocar até mesmo a violência, vista como marginalidade. Como consequência, a escolarização fica prejudicada e muitos alunos não aprendem a ler e escrever, o que, em algumas interpretações construtivistas, é apenas um indicativo de que a construção do conhecimento ainda está em processo.

Diante das dificuldades geradas pela mudança de metodologia - que não trouxe uma solução para os antigos problemas de aprendizagem - novas reformas foram propostas, fundamentadas no discurso dos ideais construtivistas da educação; como um processo de construção de conhecimento dependente da maturação das estruturas mentais. Esse discurso passou a funcionar como um dispositivo, conceito definido por Foucault (1977) como estratégia de manipulação do poder, posteriormente retomado por Agamben (2009) como (...) qualquer coisa que possa capturar, orientar, determinar, antecipar, modelar e assegurar os gestos, as condutas, as opiniões e os discursos dos sujeitos [...] (AGAMBEN, op. cit., p. 40). Assim, uma nova reforma foi implantada, pela lei 9394/96, que mudou o sistema seriado para o sistema de Progressão Continuada, e acabou com a repetência durante os ciclos. Embora seja importante compreender que o aluno merece aprender sem o peso da repetência e que o tempo e o espaço deveriam ser organizados de modo a promover o desenvolvimento, é também importante estar atento à intenção de camuflar a não aprendizagem, para que o aluno possa avançar no fluxo regular.

A implantação desorganizada dessas reformas trouxe duas consequências que se relacionam ao fracasso escolar: os alunos seguem até fases muito adiantadas da escolarização, muitas vezes sem saber ler e escrever, o que inevitavelmente afeta a formação de conceitos previstos pelo currículo básico da educação brasileira e 
desobriga os educadores a se preocuparem com a qualidade do ensino e com a reflexão sobre o que é educar.

Em um contexto pedagógico centrado no aluno, visto como responsável pela construção de seu próprio conhecimento, a dificuldade em aprender passa a ser vista como prova de falha na sua capacidade inata. Como essa capacidade se relaciona às atividades do Sistema Nervoso, as dificuldades são atribuídas a um número cada vez maior de patologias que, no dizer de Moysés e Collares (1992), são criadas e exploradas para justificar, no sujeito - e não nas instituições que o cercam - um defeito. Em consequência dessas práticas e concepções equivocadas, ocorre a medicalização da educação, para tratar das doenças do não aprender. Nesse contexto, a medicina é convocada para resolver os problemas do sistema educacional.

As críticas feitas à metodologia pedagógica vigente não pretendem defender a volta do ensino tradicional, mecanicista e descontextualizado, mas visam justificar a necessidade de se repensar as práticas pedagógicas na escola. Essa questão é relevante, pois a escola tem uma função histórica de, ao ensinar a ler e a escrever, garantir o acesso à diversidade de conhecimentos aos quais os alunos têm direito.

\section{A MEDIAÇÃO NA NEUROLINGUÍSTICA DISCURSIVA}

É nessa busca de compreensão acerca dos processos de ensino e aprendizagem que a teorização de Coudry (1986) sobre a construção partilhada de sentidos é oportuna. O quadro teórico da ND abre um campo muito fértil para as discussões sobre o que é mediar nas práticas pedagógicas, visando construir sentidos sobre os objetos de conhecimento nas diferentes disciplinas curriculares. Essa construção de sentidos pautada na ND, independentemente do conteúdo, reconhece no aluno um sujeito de linguagem, posicionado historicamente e dependente de interações significativas que estabelece em seu meio. Esse reconhecimento e a análise crítica do ambiente escolar possibilitam a percepção de que as referidas dificuldades de aprendizagem não têm origem nos sujeitos e que surgem, provavelmente, em função de um contexto pedagógico alienante que impacta o desenvolvimento cognitivo, na medida em que não promove associações funcionais que decorrem do uso significativo da linguagem; associações que são previstas e necessárias à compreensão do conhecimento sistematizado.

Luria (1979) destaca que a maioria dos conhecimentos que o homem dispõe não é resultado da própria experiência, mas sim, adquirida pela experiência histórica de sua espécie, transmitida pela linguagem. Mecacci (1987) afirma que, embora o cérebro humano seja o mais eficiente dentre todas as espécies, para adquirir novas organizações funcionais em suas relações sociais é, ao mesmo tempo, o mais impotente, se privado das influências sociais. Luria (1977) alerta que há um padrão comum ao Sistema Nervoso e que as formas complexas de atividade humana não são propriedades de um psiquismo previamente existente. As formas complexas são, sim, resultado da formação do sujeito ao longo de sua história, que deixa vestígios na estrutura de seus processos psíquicos. A compreensão de 
Luria $(1977 ; 1979)$ das funções cerebrais superiores que caracterizam o homem (atenção, percepção, memória, raciocínio intelectual, etc) está relacionada à sua visão de cérebro como um órgão dinâmico, plástico e de funcionamento integrado, profundamente relacionado ao ambiente sócio-histórico em que se desenvolve.

Freud $(1891 ; 1895)$, em seus trabalhos pré-psicanalíticos, se contrapôs à ideia de que as informações estão estocadas nas células nervosas cerebrais e trouxe uma contribuição essencial para a compreensão de um funcionamento cerebral dinâmico. $\mathrm{O}$ autor direcionou seus estudos para o entendimento de como as informações ficariam representadas no cérebro, modificando o conceito de representação então vigente e propondo que seu correspondente fisiológico fosse da natureza de um processo. Nesse processo, um fluxo energético percorreria as células nervosas a partir dos órgãos dos sentidos, atingindo as zonas corticais e, posteriormente, seria descarregado nos órgãos motores. Envolve, dessa forma, todo o corpo.

Em outras palavras, Freud $(1981 ; 1895)$ explica que o processo de representação de um conceito se inicia nos órgãos dos sentidos, através de percepções vindas do ambiente, geradas por diferentes tipos de energia que modificam o potencial energético dos neurônios receptores e se espalham pelas vias neuronais. Como as percepções acerca de uma informação são variadas, elas vão sendo reorganizadas ao longo de sua condução da medula ao córtex: sensações vão sendo associadas a outras sensações. Ao final, esse processo associativo origina a representação, que pode ser definida como uma construção mental. É dentro desse processo fisiológico que Freud $(1891$; 1895) descreve a formação da palavra com significado, ou seja, como um conceito: associações perceptivas visuais, acústicas e cinestésicas formam a representação de objeto que se une à representação de palavra que, por sua vez, é formada por associações perceptivas acústicas, motoras e também visuais, no caso da leitura e escrita. Assumindo que o processo associativo se dá por um fluxo de energia que percorre o Sistema Nervoso, Freud concluiu que as vias associativas neuronais se modificam após as passagens da energia, relacionadas a determinadas situações perceptivas, de forma a facilitar seu uso caso estas situações se apresentem novamente. De acordo com o autor (1891;1895), as vias ficam facilitadas pela intensidade energética das associações - ligadas a estados emocionais significativos, ou pela frequência de uso - repetição do processo.

Vias facilitadas podem ser rememoradas de acordo com a necessidade e, em alguns casos, resistir a determinadas lesões, como nos casos de afasia. Afirma que o desenvolvimento psíquico fica garantido porque novas associações vão sempre sendo adicionadas ao que foi primariamente associado. Chamou a esse importante processo de superassociação, esclarecendo que para que ele exista é preciso ocorrer um estado de identidade entre as associações anteriormente estabelecidas e as novas como, por exemplo, quando a criança que lê letras impressas tem que relacioná-las aos novos caracteres da escrita à mão. $\mathrm{O}$ entendimento desse conceito é muito importante para intervir (e compreender) no processo de aprendizagem escolar. 
Ao descrever a formação do conceito pela união da representação da palavra com a representação de objeto, Freud $(1891 ; 1895)$ evidencia o papel essencial da linguagem na formação do pensamento. Considerando que o exercício da linguagem se dá em contextos sociais bem definidos, podemos entender melhor a constituição sócio-histórica dos sujeitos. Rizzuto (1990) chama a atenção para o fato de que a representação é uma construção mental estimulada pela percepção do objeto em si, que passa, então, a ser qualificado subjetivamente, distanciando-se do objeto real.

Os trabalhos de Freud $(1891 ; 1895)$ muito contribuíram para a compreensão da articulação que se estabelece entre os processos psíquicos e as interações significativas para os sujeitos, por meio da linguagem, permitindo discutir a fragilidade de uma metodologia pedagógica baseada em supostas capacidades inatas do aluno para construir seu próprio conhecimento.

Com esses estudos de Freud (1891; e 1895), é possível reconhecer ainda mais a relevância da proposta de Coudry (1986) de construção partilhada de sentidos para as práticas de ensino-aprendizagem. Na escola estão em jogo conhecimentos elaborados (e sistematizados) historicamente, o que requer uma revisão do conceito de mediação.

Mediar em vivências significativas, mesmo os conteúdos oriundos de um discurso coletivo (curricular, padronizado pela pretensão de uma objetividade que lhe garanta a repetibilidade), passa a ser entendida como a busca pela singularidade das associações feitas pelo aluno durante sua história para que, através da linguagem, se estabeleça o estado de identificação entre essas informações e as novas percepções (Righi-Gomes, 2014), permitindo a inserção do sujeito na repetição histórica, isto é, em um ato de repetir atribuindo sentido (Orlandi, 1988).

Essa possibilidade dá um novo sentido à chamada realidade do sujeito - tão propagada pela metodologia construtivista - como o espaço em que supostamente se dá a construção do conhecimento, mas que pode resultar, a nosso ver, em uma redução da compreensão do conteúdo curricular. Na perspectiva da ND, a realidade do sujeito é simbólica e se busca, pela mediação atenta e significativa, potencializar o uso das vias facilitadas promovendo processos identificatórios e, portanto, superassociações, o que amplia as suas condições aprendizagem (RighiGomes, 2014).

Vygotsky (1926;1934), acreditando que a aprendizagem precede o desenvolvimento e propondo o conceito de "zona de desenvolvimento iminente", isto é, a distância entre o nível de desenvolvimento em que a criança está e o nível que atinge pelo aprendizado de um conteúdo, define dois tipos de conceitos diferenciados pela sua estrutura de desenvolvimento e pela atitude em relação aos objetos: conceitos cotidianos e científicos. A descrição do desenvolvimento desses conceitos pode ser aproximada ao processo de superassociação proposto por Freud (1891;1895). Para Vygotsky (1926), os conceitos cotidianos se desenvolvem muito antes de a criança ingressar na escola; contudo, o ingresso na escola significa uma possibilidade para desenvolver para conceitos científicos. O autor esclarece que esse conhecimento nunca parte do desconhecido: quando o conceito científico se relaciona, através da linguagem, com o conceito cotidiano, adquire sentido e passa 
a constituir o pensamento cognitivo consciente. Vygotsky esclarece, no entanto, que para a aprendizagem de um conceito não é necessária a experiência real do aluno, mas é importante que o professor ajude o aluno a relacionar os conteúdos com a experiência que ele tem. Isso desloca o professor da sua posição de autoridade, levando-o a contextualizar as situações de ensino-aprendizagem para que o aluno possa entender os enunciados do campo em questão. Essa modificação na postura do professor altera sua relação com o aluno que se tornará, então, um interlocutor ativo, uma vez que suas experiências passam a ser valorizadas. Isso torna o processo um partilhar de sentidos, uma prática fundamental para que os alunos se filiem aos conhecimentos historicamente. Isso se torna possível na medida em que se percebe que a qualidade da mediação depende da postura do professor e do reconhecimento de seu aluno como "sujeito de linguagem".

Como exemplo dessa possibilidade pedagógica, na área de ciências, trago uma prática realizada em 2013 (Righi-Gomes, 2014), em uma sala de oitavo ano do Ensino Fundamental II, com alunos de 13 e 14 anos. A maioria desses alunos apresenta grande defasagem no aprendizado de leitura e escrita e, consequentemente, na compreensão de conceitos.

Nessa prática, o objetivo era permitir que os alunos retomassem os conceitos relacionados às funções do coração e do sangue na nutrição das células para o funcionamento do corpo. Essa retomada pretendia que a compreensão de que o sangue transporta oxigênio e nutrientes para as células, impulsionado pelo coração, passasse a fazer sentido suficiente para que o conteúdo fosse aprendido.

Inicio a prática perguntando ao grupo se alguém sabe a importância do coração para o corpo. A resposta que recebo vem baseada em um conceito cotidiano muito facilitado: "se ele parar a gente morre". Embora a resposta esteja correta, ela não explica o que causa a morte na parada cardíaca e que essa causa está relacionada à necessidade constante de nutrição celular.

Visando uma vivência significativa da linguagem durante o processo, coloco na lousa a frase: "Eu $\bullet$ o $8^{\circ} \mathrm{C}$ ". Praticamente todos os alunos reagem com entusiasmo, entendendo que o desenho do coração significa "amor".

Promovo, a partir dessa reação, uma discussão sobre o motivo pelo qual o amor está relacionado ao coração, um órgão muscular como vários outros do organismo. Nesse contexto, proponho, então, uma rápida encenação de duas pessoas apaixonadas que se encontram repentinamente, questionando sobre qual é a sensação que o coração provoca nas pessoas nessa situação. Todos respondem que o coração dispara. Relaciono esse disparo a uma maior necessidade energética do corpo na situação indicada, especialmente das células do cérebro, para tomar decisões e desempenhar um papel adequado na conquista. A partir dessa discussão, que através da linguagem orienta possíveis associações que atendam ao objetivo proposto, relaciono o trabalho do coração à nutrição celular em outras atividades humanas, como nos esportes, bem como nas atividades metabólicas do corpo, o que nos leva a compreender as causas das mortes relacionadas ao coração. Dessa forma, os conceitos científicos adquiriram sentido em um processo construído ao serem associados aos conceitos cotidianos, por meio da linguagem e da mediação do professor, em um contexto significativo. 
A sistematização dos conteúdos para alunos pouco familiarizados nos processos de escrita e leitura impõe à prática pedagógica algumas dificuldades. Por este motivo, muitas vezes, essa prática se torna padronizada e sem sentido. Acreditando que a função de autor pode ser exercida por aqueles que pouco sabem ler e escrever e com o intuito de sistematizar o conteúdo em questão, foi proposta uma atividade de produção conjunta de um texto. A escrita emerge das sugestões dos alunos que discutem a melhor maneira, dentre as várias propostas, de fazer na lousa o registro sobre as funções do coração:

"Todo mundo pensa que o amor mora no coração, mas isso não é verdade. Pensamos assim porque o coração dispara quando vemos a pessoa que amamos ou quando levamos um susto. As células do nosso corpo sempre precisam de glicose e oxigênio para sobreviver e trabalhar, mas quando acontece uma coisa que não esperamos as células vão ter que trabalhar um pouco mais, especialmente as do cérebro, para resolver o que vamos fazer. Por isso, o coração tem que bater mais rápido para enviar mais oxigênio e glicose para as células ficarem com mais energia para o trabalho. A sensação provocada pelo disparo no coração faz a gente pensar que o amor está lá."

Produção conjunta de texto sobre função do coração da $8^{\circ} \mathrm{C}$

Os alunos, assim, se sentem ouvidos e valorizados em suas falas, ampliando suas chances de aprender os conceitos, de vivenciar uma atividade significativa de leitura e de escrita, de assumir posições e, consequentemente, responsabilidades durante o processo de ensino-aprendizagem.

Ainda assim, cabe refletir sobre uma importante contribuição de Coudry (2010) ao alertar que as representações novas e antigas coexistirão no funcionamento cerebral e uma instabilidade em seu uso deve ser prevista e não julgada. Muitas vezes, segundo a autora, é por desconhecer a mobilidade da barra que separa o velho do novo que muitos processos de avaliação pedagógica resultam em julgamentos negativos sobre a aprendizagem do aluno. A mesma autora, em 1996, alerta que as falhas na utilização dessas associações não devem ser vistas como evidências de erro, mas podem ser consideradas como dados-achados. A noção de dado-achado proposta por Coudry (1996) se traduz como uma informação que resulta da relação recíproca dos recursos utilizados pelos interlocutores durante os processos interativos e a teoria. Do ponto de vista da intervenção pedagógica, o erro visto como dado-achado pode mostrar o caminho percorrido pelo aluno no processo, dando indicações das associações que o sujeito já fez e daquelas que ainda pode fazer com relação ao conteúdo tematizado, promovendo um novo sentido para as práticas avaliativas.

\section{CONSIDERAÇÕES FINAIS}

Os pressupostos teóricos da ND possibilitam que o aluno seja visto como um sujeito de linguagem e, portanto, um sujeito histórico. Como tal, sua aprendizagem 
é dependente do simbólico, da linguagem adquirida e desenvolvida em interações sociais. A mediação promove a compreensão das significações culturais/simbólicas pela criança através de situações interativas que só são possíveis entre a criança e o outro. Freud (1895), ao descrever a vivência dos sujeitos na aquisição da linguagem, afirma que é condição humana aprender com o seu semelhante.

A escola deve se preocupar em dar condições para que o conhecimento historicamente construído seja compreendido pelo aluno, em contexto institucional que tem por responsabilidade a construção de sentidos nos processos de ensinoaprendizagem.

É necessário perceber a importância da mediação nas práticas pedagógicas para que o conhecimento acerca de um objeto adquira um sentido histórico para sujeitos que têm por condição aprender com o outro.

Os conceitos propostos pela ND vêm se posicionar como contradispositivos aos dispositivos que levam à patologização ou à marginalização de crianças, pois o não aprender pode estar mais relacionado ao atual contexto educacional do que ao funcionamento fisiológico do Sistema Nervoso.

Diante das dificuldades apresentadas pela escola, a teorização produzida na ND se apresenta como uma possibilidade de reflexão de como se contrapor às demandas impostas pelo sistema político-educacional e de como manter vivo o desejo da escola em fornecer elementos simbólicos aos envolvidos no processo, promovendo a autonomia da escola para educar.

Cabe, portanto, para finalizar este texto, agradecer à Profa. Coudry, por partilhar, ao longo de todos esses anos, sentidos que ajudam aqueles que trabalham em sala de aula a ressignificar os sentidos do possível.

\section{REFERÊNCIAS}

AGAMBEN, G. O que é contemporâneo e outros ensaios. Chapecó: Ed. Argos, 2009.

COUDRY, M. I. H. (1986). Diário de Narciso. Discurso e afasia: análise discursiva de interlocuções com afásicos. Tese de doutorado. Unicamp, Campinas, 1986. Publicada em livro, São Paulo: Martins Fontes, 1988.

COUDRY, M. I. H. O que é dado em Neurolinguística? In: CASTRO, M. F. (Org.) O método e o dado no estudo da linguagem. Campinas: Ed. Unicamp, 1996.

COUDRY, M. I. H. Relatório de Pesquisa do Projeto Integrado em Neurolinguística: avaliação e banco de dados. CNPq, 2010 (impresso, 65 pp.).

COUDRY, M. I. H.; FREIRE, F. M. O trabalho do cérebro e da linguagem: a vida na sala de aula. Campinas: Cefiel/IEL/Unicamp, 2005.

DUARTE, N. Vigotski e o “aprender a aprender". Crítica às apropriações neoliberais e pós-modernas da teoria vigotskiana. Campinas: Autores Associados, 2012.

FERREIRO, E. Reflexões sobre alfabetização. São Paulo: Ed. Cortez, 1996. 
FOUCAULT, M. História da Sexualidade I: a vontade de saber. Rio de Janeiro: Ed. Graal, 1977.

FREUD, S. A interpretação das afasias: um estudo crítico. Lisboa; Marcilio ed. [1981] 1977.

FREUD, S. Proyecto de una psicologia para neurologos. Madrid: Editorial Biblioteca Nueva, [1895/1950] 1981.

LURIA, A. R. Curso de Psicologia Geral: Introdução Evolucionista à Psicologia. v. 1. São Paulo: Civilização Brasileira, 1979.

LURIA, A. R. Desenvolvimento Cognitivo. São Paulo: Ed. Ícone, 1977.

MECACCI, L. Conhecendo o cérebro. São Paulo: Nobel, 1987.

MOYSÉS, M. A. A.; COLLARES, C. A. L. A história não contada dos distúrbios de aprendizagem. Cadernos CEDES 28, p. 31-48, 1992.

OLIVEIRA, R. P. Da universalização do ensino fundamental ao desafio da qualidade: uma análise histórica. Educação e Sociedade 28, n. 100, p. 661-690, 2007.

ORLANDI, E. P. Análise do discurso e leitura. São Paulo: Cortez/Autores Associados/Ed. Unicamp, 1988.

RIGHI-GOMES, M. J. I. Reflexões sobre práticas docentes à luz da Neurolinguística Discursiva. Tese de doutorado. Unicamp. Campinas, 2014.

RIZZUTO, A. M. The origins of Freud's concept of object representation ('objektvorstellung') in his monograf 'On aphasia': its theorical and techinal importance. Int. J. Psycho-Anal. 71, p. 241248,1990 .

VYGOTSKY, L. S. Pensamiento e habla. Buenos Aires: Colihue Clássica, [1934] 2007.

VYGOTSKY, L. S. Psicologia Pedagógica. São Paulo: Martins Fontes, [1926] 2004. 